\title{
2, 4, 6-Trihidroksi Benzofenon dari Kulit Batang Garcinia balica Miq
}

\author{
Retno Purbowati dan Taslim Ersam \\ Jurusan Kimia, Fakultas Matematika dan Ilmu Alam, Institut Teknologi Sepuluh Nopember (ITS) \\ Jl. Arief Rahman Hakim, Surabaya 60111 Indonesia \\ e-mail:paktichem@gmail.com
}

\begin{abstract}
Abstrak-Penelitian ini bertujuan untuk mengisolasi senyawa metabolit sekunder dari ekstrak etil asetat kulit batang Garcinia balica Miq. Proses ekstraksi dengan pelarut etil asetat didapatkan fraksi kering, kemudian difraksinasi menggunakan metode Kromatografi Kolom Gravitasi (KKG) dan dilanjutkan dengan metode Kromatografi Eksklusi Ukuran. Senyawa yang diisolasi berupa padatan amorf berwarna kuning kecoklatan dengan titik leleh sebesar $215-216^{\circ} \mathrm{C}$. Penentuan struktur senyawa dilakukan dengan analisis UV, IR, ${ }^{1} \mathrm{H} \operatorname{dan}^{13} \mathrm{C}$ NMR. Senyawa yang diisolasi diketahui merupakan senyawa 2,4 , 6-trihidroksi benzofenon (1).
\end{abstract}

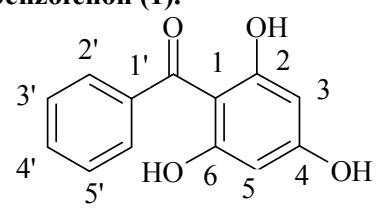

Kata Kunci-Garcinia balica; benzofenon.

\section{PENDAHULUAN}

I NDONESIA memiliki hutan tropis yang sangat luas dan kaya dengan aneka ragam spesies tumbuhan [1]. Keanekaragaman ekosistem dalam hutan tropis mempunyai hubungan langsung dengan tingginya keanekaragaman hayati dan tingkat endemik [2]. Garcinia merupakan salah satu genus tumbuhan tropis dari famili Clusiaceae. Tumbuhan ini merupakan salah satu genus terbesar dengan 400 spesiesnya tersebar luas di kawasan tropis Asia, Kaledonia Baru dan Polinesia [3]. Penelitian mengenai kandungan kimia dari genus Garcinia telah banyak dilakukan, diantaranya adalah guttiferones Q-S [4], 5'-bromo-2'-hidroksi-4, 4; 6'trimetoksi chalkon [5], dulcisoflavon [6]. Genus ini dilaporkan banyak kandungan senyawa santon teroksigenasi dan terprenilasi [7]. Tetapi beberapa diantaranya juga menghasilkan senyawa benzofenon terprenilasi, biflavonoid dan kumarin [8].

Garcinia balica Miq, salah satu spesies dari genus Garcinia merupakan tumbuhan endemik yang dapat ditemukan di Taman Nasional Baluran, Situbondo, Jawa Timur. Garcinia balica Miq dikenal dengan nama daerah yaitu mundu alas. Tumbuhan ini digunakan secara tradisional sebagai obat kulit, antibengkak, antimalaria, dan antihipertensi [9]. Hasil penelitian sebelumnya mengenai kandungan senyawa metabolit sekunder dari tumbuhan ini diantaranya adalah senyawa 5,7-dihidroksi8-(1-,2-dihidroksi-3-metilbutenil-3)-4-fenilkumarin dari ekstrak etil asetat pada bagian batang yang memiliki aktivitas antioksidan tinggi, 5-hidroksi 4-fenilkumarin dan 7-hidroksi 4-fenilkumarin.

Hal ini menunjukkan bahwa tumbuhan G.balica Miq mempunyai banyak kandungan senyawa metabolit sekunder aktif. Bagian-bagian tertentu pada tumbuhan biasanya berpeluang untuk mendapatkan senyawa yang sama atau bahkan berbeda sehingga dibutuhkan penelitian lebih lanjut terhadap G.balica ini.

\section{METODOLOGI PENELITIAN}

\section{A. Fraksinasi}

Sebanyak $603.0 \mathrm{mg}$ fraksi kering ekstrak etil asetat kulit batang $G$. balica dilakukan pemisahan menggunakan metode kromatografi kolom gravitasi. Pemisahan menggunakan pelarut etil asetat: n-heksana dengan peningkatan kepolaran sebesar 40\%, 50\%, 70\%, etil asetat $100 \%$ dan metanol $100 \%$.

Hasil dari pemisahan ini ditampung pada vial $100 \mathrm{~mL}$ sebanyak 27 vial dengan volume tampungan sekitar 50 $\mathrm{mL}$. Selanjutnya dilakukan pemantauan noda pada semua vial dengan mengelusi plat KLT menggunakan pelarut etil asetat: n-heksana $80 \%$ dengan memilih vial bernomor genap.

Proses selanjutnya dilakukan penggabungan vial berdasarkan gabungan $\mathrm{Rf}$ yang sama pada plat KLT. Hasilnya didapatkan lima fraksi yaitu A, B, C, D dan E.

Setelah didapatkan lima fraksi, dilakukan pemisahan fraksi B menggunakan metode sephadex LH-20 dengan eluen metanol: diklorometana 1:1 menghasilkan 10 subfraksi yaitu B1-B10. Selanjutnya dilakukan pemantauan noda senyawa menggunakan KLT.Profil noda dengan $\mathrm{Rf}$ yang sama digabungkan menghasilkan BG1(0.7 mg), BG2 (2 mg), BG3(.3 mg), BG4(4 mg) dan BG5(10.5 mg). Dari hasil KLT, BG5 menunjukkan spot noda tunggal yang mengindikasikan bahwa subfraksi tersebut sudah murni.

\section{B. Proses Pemurnian dan Uji Kemurnian}

Pada proses uji kemurnian, dilakukan pengujian 3 eluen berbeda dengan menggunakan perbedaan kepolaran eluen. Proses ini menggunakan campuran eluen yaitu metanol: diklorometana $20 \%$, etil asetat: $n$ heksana $80 \%$, dan etil asetat: klorofom $70 \%$. Proses ini untuk mengetahui profil noda tunggal pada posisi atas, tengah, dan bawah.

\section{Pengujian Spektrofotometer UV}

Sebanyak $1 \mathrm{mg}$ sampel dilarutkan dalam $10 \mathrm{~mL}$ metanol p.a. dan digunakan sebagai larutan stok dalam pengujian. Larutan metanol-sampel diukur absorbansinya pada $\lambda$ 200-600 nm dengan menggunakan blanko metanol. Larutan sampel yang sama ditambah 3 tetes $\mathrm{NaOH}$ dan diukur absorbansinya.

Larutan sampel yang baru ditambah 6 tetes $\mathrm{AlCl}_{3}$ dan diukur pula absorbansinya. Dilakukan hal yang sama untuk larutan sampel yang telah ditambah $\mathrm{AlCl}_{3}$ dan 3 
tetes $\mathrm{HCl}$. Kemudian diambil larutan sampel baru dan ditambah $\pm 100 \mathrm{mg} \quad \mathrm{CH}_{3} \mathrm{COONa}$ lalu diukur pula absorbansinya. Prosedur yang sama dilakukan untuk larutan sampel yang telah ditambah $\mathrm{CH}_{3} \mathrm{COONa}$ dan $\pm 100 \mathrm{mg} \mathrm{H}_{3} \mathrm{BO}_{3}$.

\section{Pengujian Spektrofotometer IR}

Senyawa hasil isolasi diambil $\pm 1 \mathrm{mg}$ dan digerus dalam $\mathrm{KBr}$ sampai homogen. Dibuat pelet dengan ketebalan $\pm 1 \mathrm{~mm}$ dan diukur serapannya pada bilangan gelombang 400-4000 $\mathrm{cm}^{-1}$.

\section{E. Pengujian Spektrofotometer NMR}

Sebanyak $20 \mathrm{mg}$ senyawa hasil isolasi dilarutkan dalam aseton- $\mathrm{d}_{6}$. Selanjutnya sampel yang sudah dilarutkan tersebut diinjeksikan ke dalam tabung NMR dan dianalisis untuk mendapatkan data spektra ${ }^{1} \mathrm{H}-\mathrm{NMR}$ dan ${ }^{13} \mathrm{C}$-NMR.

\section{HASIL DAN PEMBAHASAN}

\section{A. Ekstraksi dan Fraksinasi}

Fraksi kering berbentuk serbuk kasar berwarna kuning dengan massa yaitu $601.0 \mathrm{mg}$. Sebelum dilakukan proses pemisahan, terlebih dahulu dilakukan uji eluen untuk mengetahui eluen yang tepat pada proses pemisahan. Fraksi kering diambil $\pm 1 \mathrm{mg}$ dan diuji kelarutannya. Dari hasil uji kelarutan, diketahui bahwa fraksi ini larut pada metanol dan etil asetat dan tidak larut pada diklorometana dan $\mathrm{n}$-heksana. Selanjutnya, fraksi yang larut dipindahkan ke dalam vial berukuran $10 \mathrm{ml}$ dan ditambahkan metanol sampai konsentrasinya tidak terlalu pekat. Dilakukan pengujian eluen dengan tingkat kepolaran yang berbeda yaitu etil asetat-diklorometana $50 \%$, etil asetat-n-heksana $70 \%$, dan metanoldiklorometana $50 \%$. Pemisahan yang bagus didapat dengan menggunakan eluen etil asetat-n- heksana $70 \%$, maka untuk proses pemisahan selanjutnya akan digunakan eluen tersebut dengan tingkat kepolaran yang bervariasi dimulai dari kepolaran yang rendah.Hal ini bertujuan agar senyawa-senyawa di bagian atas dapat terelusi terlebih dahulu.

Proses pemisahan menggunakan metode kromatografi kolom gravitasi untuk mendapatkan hasil pemisahan yang baik, karena senyawa target berjarak sangat dekat dengan senyawa lainnya. Eluen yang digunakan yaitu etil asetat: n-heksana $40 \%, 50 \%, 70 \%$, etil asetat $100 \%$, dan metanol $100 \%$. Pemisahan ditampung pada vial $100 \mathrm{ml}$ dengan menampung sekitar $70 \%$ volume. Setiap peningkatan kepolaran, dilakukan monitoring terlebih dahulu apakah noda yang muncul sudah mulai berkurang intensitasnya. Dari hasil tersebut, didapatkan sebanyak 27 vial.Selanjutnya, semua hasil tampungan tersebut dilakukan uji KLT untuk mengetahui profil noda. Pengujian dilakukan pada vial bernomor genap.

Profil noda yang sama kemudian digabung dan diperolehtkan subfraksi A $(98.3 \mathrm{mg})$, B $(110 \mathrm{mg}), \mathrm{C}$ (150.33 mg), D (81.5 mg), E (98.9 mg) (Gambar 4.3). Dilakukan proses pemisahankembali menggunakan sephadex LH-20 pada subfraksi B yang menghasilkan B1 (0.2 mg), B2(0.5 mg), B3 (0.99), B4 (1.01 mg), B5 (0.09 $\mathrm{mg}), \mathrm{B} 6$ (0.21 mg), B7 (1.35 mg), B8 (2.65 mg), B9 (9.5 $\mathrm{mg})$, B10 (1 mg). Dari hasil pemisahan menggunakan sephadex LH-20, dilakukan uji KLT untuk mengetahui profil noda dengan $\mathrm{Rf}$ yang sama. Berdasarkan hasil monitoring KLT, subfraksi B1-B10 digabung menghasilkan subfraksi BG1 (0.7 mg), BG2 (2 mg), BG3 (0.3 mg), BG4 (4 mg) dan BG5 (10.5 mg).nDilakukan pemantauan kembali untuk mengetahui profil noda. Hasilnya didapat bahwa profil noda BG5 tunggal. Karena noda terlihat tunggal, maka dilakukan uji tiga eluen dengan tingkat kepolaran berbeda untuk mendapatkan hasil noda tunggal pada tiga titik yaitu atas, tengah dan bawah.

\section{B. Proses Pemurnian dan Uji Kemurnian}

Dari uji tiga eluen, untuk noda tunggal posisi atas didapat dengan menggunakan eluen metanoldiklorometana 20\%. Noda tunggal pada posisi atas menunjukkan bahwa sudah tidak terdapat senyawa lain di posisi bawah senyawa tersebut. Untuk noda tunggal posisi tengah, didapat dengan eluen etil asetatdiklorometana $80 \%$. Posisi noda tunggal di tengah menunjukkan bahwa sudah tidak terdapat senyawa lain di posisi atas dan bawah senyawa tersebut. Pada posisi noda tunggal bawah, eluen yang digunakan yaitu etil asetatkloroform $70 \%$. Posisi noda tunggal bawah menunjukkan bahwa tidak terdapat senyawa lain di atas senyawa tersebut.

Setelah dilakukan uji 3 eluen, maka dilakukan uji titik leleh. Padatan hasil isolasi senyawa berbentuk serbuk halus kecoklatan dengan massa sebesar $10.5 \mathrm{mg}$. Uji titik leleh mendapatkan hasil yaitu sebesar $215-216^{\circ} \mathrm{C}$. Hasil tersebut sesuai dengan indikator senyawa murni yang mulai meleleh sampai meleleh seluruhnya dengan rentang $\pm 1^{0} \mathrm{C}$

\section{Penentuan Struktur}

Spektrum UV-Vis (Gambar 1) menunjukkan spektrum UV-Vis dengan dua puncak serapan pada $290 \mathrm{~nm}$ (pita II) dan $325 \mathrm{~nm}$ (pita I). Pada penelitian ini, spektrum pada pita II berada pada panjang gelombang $290 \mathrm{~nm}$. Hal ini mengindikasikan adanya eksitasi elektron dari $\pi \rightarrow \pi^{*}$ yang merupakan kromofor khas sistem ikatan rangkap terkonjugasi $(-\mathrm{C}=\mathrm{C}-\mathrm{C}=\mathrm{C}-)$ pada cincin aromatik. Pada pita I dengan panjang gelombang $325 \mathrm{~nm}$ menunjukkan adanya eksitasi elektron dari $\mathrm{n} \rightarrow \pi^{*}$ yang merupakan kromofor khas untuk sistem terkonjugasi dari heteroatom dengan ikatan rangkap terkonjugasi $(-\mathrm{C}=\mathrm{C}=\mathrm{C}=\mathrm{O})$.

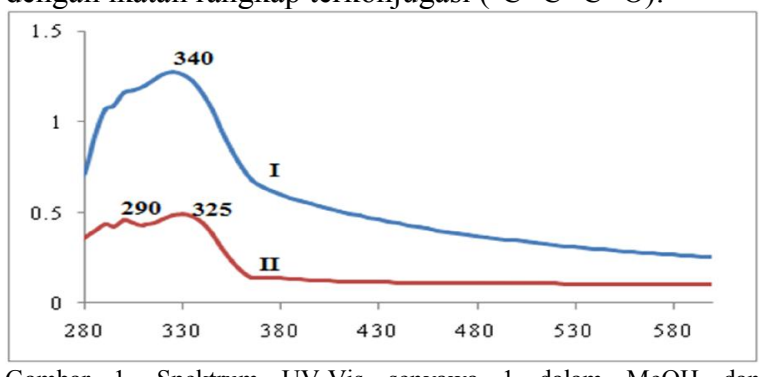

Gambar 1. Spektrum UV-Vis senyawa 1 dalam $\mathrm{MeOH}$ dan $\mathrm{MeOH}+\mathrm{NaOH}$

Setelah ditambahkan $\mathrm{NaOH}$ terjadi pergeseran batokromik pada pita I sebesar $15 \mathrm{~nm}$ dari panjang gelombang $325 \mathrm{~nm}$ menjadi $340 \mathrm{~nm}$.Hal ini terjadi karena pengaruh auksokrom. Auksokrom merupakan gugus fungsi yang tidak menyerap energi cahayanya sendiri akan tetapi dapat meningkatkan intensitas warna yang diserap kromofor karena terdapat ikatan rangkap terkonjugasi, seperti gugus - $\mathrm{OH} \mathrm{[10].} \mathrm{Gugus} \mathrm{hidroksi}$ merupakan pendorong elektron yang kemudian 
mengalami kesetimbangan keto-enol dengan gugus karbonil yang terletak pada posisi para(Gambar 1) [11].

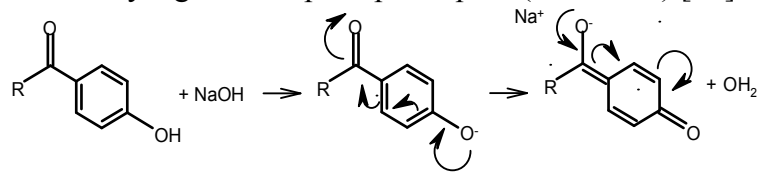

Gambar 2. Kesetimbangan keto-enol dengan $\mathrm{NaOH}$

Pada saat penambahan $\mathrm{AlCl}_{3}$ tidak terjdi pergeseran batokromik maupun hipsokromik. Tetapi ketika ditambahkan $\mathrm{HCl}$ terjadi pergeseran batokromik sebesar $50 \mathrm{~nm}$ pada pita I. Dari data tersebut dapat diketahui bahwa senyawa ini mempunyai gugus $\mathrm{OH}$ khelat tapi tidak tersubtitusi posisi orto. Ketika ditambahkan $\mathrm{CH}_{3} \mathrm{COONa}$ tidak menunjukkan adanya pergeseran batokromik tetapi pada saat ditambahkan $\mathrm{H}_{3} \mathrm{BO}_{3}$ terjadi pergeseran batokromik. Hal ini dapat disimpulkan bahwa senyawa ini tidak memiliki subtituen hidroksi pada posisi orto.

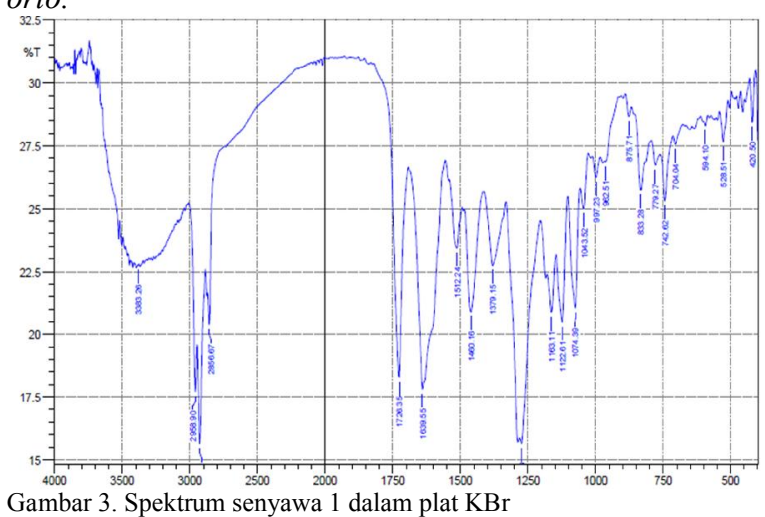

Analisis selanjutnya adalah spektrofotometer IR pada bilangan gelombang $400-4000 \mathrm{~cm}^{-1}$ yang menunjukkan beberapa pita khas dari suatu gugus fungsi. Pita-pita serapan yang khas diantaranya adalah $3383 \mathrm{~cm}^{-1}, 2926$ $\mathrm{cm}^{-1}, 2856 \mathrm{~cm}^{-1}, 1726 \mathrm{~cm}^{-1}$ dan $1639 \mathrm{~cm}^{-1}$. Pada bilangan gelombang 3100-3500 $\mathrm{cm}^{-1}$ melebar menunjukkan adanya gugus hidroksi (-OH). Bilangan gelombang 1639 $\mathrm{cm}^{-1}$ menunjukkan adanya gugus karbonil terkhelat dengan didukung bilangan gelombang pada $3383 \mathrm{~cm}^{-1}$ yang mencirikan gugus hidroksi yang terikat [12]. Selanjutnya bilangan gelombang $2926 \mathrm{~cm}^{-1}$ dan $2856 \mathrm{~cm}^{-}$ 1 menunjukkan C-H alifatik. Sedangkan serapan pada panjang gelombang $1512 \mathrm{~cm}^{-1}$ merupakan serapan khas untuk ikatan cincin aromatik, dimana data ini menguatkan data dari spektrum UV [13].

Analisis struktur berikutnya menggunakan NMR, baik ${ }^{1} \mathrm{H}-\mathrm{NMR}$ maupun ${ }^{13} \mathrm{C}$-NMR. Proses analisis menggunakan pelarut aseton- $\mathrm{d}_{6}$ dan diukur pada frekuensi $500 \mathrm{MHz}$ dan $125 \mathrm{MHz}$. Data yang diperoleh berupa pergeseran $(\delta){ }^{1} \mathrm{H}-\mathrm{NMR}$ dan ${ }^{13} \mathrm{C}-\mathrm{NMR}$ yang berisi informasi tentang jenis lingkungan proton maupun karbon, multiplisitas dan jumlah proton atau integritas. Dalam ${ }^{1} \mathrm{H}-\mathrm{NMR}$ juga dikenal data berupa konstanta kopling yang memberikan informasi berupa jarak antara 2 pergeseran pada serapan proton yang sama.

Pada spektrum ${ }^{1} \mathrm{H}-\mathrm{NMR}$, diketahui terdapat sinyal proton pada pergeseran $(\delta, \mathrm{ppm}) 12,34 \mathrm{ppm}(1 \mathrm{H}$, brs $)$ menunjukkan gugus $\mathrm{OH}$ yang terkhelat dengan karbonil. Data ini menguatkan analisis spektrum UV-Vis bahwa terdapat gugus karbonil terkhelat. Sinyal-sinyal proton pada 7,07 ppm dan 6,74 ppm $(1 \mathrm{H}, d, J=7,6 \mathrm{~Hz})$ menunjukkan sinyal proton aromatis. Pada $12,34 \mathrm{ppm}$ menunjukkan adanya gugus karbonil terkhelat, sedangkan pada sinyal $6,90 \mathrm{ppm}$ menunjukkan gugus $\mathrm{OH}$ bebas.

Tabel 1.

Data perbandingan pergeseran $(\delta)$ 1H-NMR dan 13C-NMR senyawa 1 dan senyawa 10

\begin{tabular}{|c|c|c|c|c|}
\hline \multirow{2}{*}{ NO } & \multicolumn{2}{|c|}{$\delta_{\mathrm{H}}(\mathbf{p p m})$} & \multicolumn{2}{|c|}{$\delta_{\mathrm{C}}(\mathbf{p p m})$} \\
\hline & (1) & (10) & (1) & (10) \\
\hline 1 & & & 101,96 & 105,83 \\
\hline 2 & $12,34(s)$ & $10,59(s, \mathrm{IH})$ & 161,00 & 161,71 \\
\hline 3 & $5,92(s)$ & $5,83(s, 2 \mathrm{H})$ & 94,89 & 95,75 \\
\hline 4 & & & 164,25 & 164,37 \\
\hline 5 & $5,98(s)$ & $5,83(s, 2 \mathrm{H})$ & 96,01 & 95,75 \\
\hline 6 & & & 163,33 & 161,71 \\
\hline $1^{\prime}$ & & & 145,59 & 145,13 \\
\hline 2 ' & $6,74(d, J=7,6 \mathrm{~Hz})$ & $7,68(d, J=8,2 \mathrm{~Hz}, 2 \mathrm{H})$ & 129,02 & 129,47 \\
\hline $3{ }^{\prime}$ & $5,71(d, J=11,8 \mathrm{~Hz})$ & $7,89(d, J=8,2 \mathrm{~Hz}, 2 \mathrm{H})$ & 128,71 & 133,17 \\
\hline $4^{\prime}$ & & & 84,12 & 114,35 \\
\hline 5 & & & 119,89 & 119,53 \\
\hline 6 & & & 128,71 & 133,17 \\
\hline $\mathrm{C}=\mathrm{O}$ & & & 197,76 & 197,09 \\
\hline
\end{tabular}

Analisis selanjutnya yaitu spectrum 13C-NMR. Terdapat sinyal-sinyal pada pergeseran kimia $\left(\delta_{\mathrm{C}}, \mathrm{ppm}\right)$ yaitu Pergeseran pada 197,6 ppm menunjukkan adanya gugus karbonil terkhelat dari suatu benzofenon [14]. Data tersebut menguatkan data analisis spektra UV- Vis dan IR pada pembahasan sebelumnya.

Data spektrum ${ }^{1} \mathrm{H}-\mathrm{NMR}$ dan ${ }^{13} \mathrm{C}$-NMR dari senyawa $\mathbf{1}$ kemudian dibandingkan dengan 4-(2,4,6trihydroxybenzoyl) benzonitrile (senyawa 10). Dari data perbandingan spektrum, diketahui bahwa senyawa pembanding mempunyai gugus $\mathrm{CN}$ dengan pergeseran ${ }^{13} \mathrm{C}$-NMR pada 114,35 ppm sedangkan pada senyawa 1 tidak muncul pada pergeseran tersebut sehingga dapat disimpulkan bahwa senyawa 1 tidak mempunyai subtituen CN. Perbandingan kedua senyawa tersebut dapat dilihat pada Tabel 1 .

Sesudah membandingkan data spektrum ${ }^{1} \mathrm{H}-\mathrm{NMR}$ dan ${ }^{13} \mathrm{C}$-NMR antara senyawa $\mathbf{1}$ dengan senyawa $\mathbf{1 0}$ serta analisis UV dan IR sehingga senyawa $\mathbf{1}$ dapat digambarkan sebagai berikut:<smiles>O=C(c1ccccc1)c1c(O)cc(O)cc1O</smiles>

\section{KESIMPULAN}

Dari isolasi ekstrak etil asetat batang Garcinia balica Miq didapatkan senyawa 2, 4, 6-trihidroksi benzofenon (1). Senyawa ini berupa powder berwarna kuning kecoklatan dengan titik leleh sebesar $215-216^{\mathrm{O}} \mathrm{C}$.

\section{UCAPAN TERIMA KASIH}

Penulis mengucapkan terima kasih kepada tim penelitian Laboratorium Kimia Bahan Alam dan Sintesis, Jurusan Kimia FMIPA ITS serta semua pihak yang turut membantu. 


\section{DAFTAR PUSTAKA}

[1] Steinlin dkk. 1988. Menuju Kelestarian Hutan Edisi Pertama. Jakarta: Yayasan Obor Indonesia.

[2] Ersam, T. (2001). Senyawa Kimia Mikromolekuler Beberapa Tumbuhan Artocarpus Hutan Tropika Sumatera Barat. Disertasi, PPs,ITB, Bandung.

[3] Merza, J. (2004). Prenylated Xanthon and Tocotrienol from Garcinia virgate. Phytochemistry. 65: 2915-2920.

[4] Nguyen, Hiep D., Trinh, Bihn T.D., Nguyen*, Lien-Hoa D. (2011). Guttiferones $Q-S$, cytotoxic polyisoprenylated benzophenones from the pericarp of Garcinia cochinchinensis. Phytochemistry Letters 4. 129-133.

[5] Iilyas ${ }^{\mathrm{a} *}$, M., Perveen ${ }^{\mathrm{a}}$, Mehtab, Shafiullah ${ }^{\mathrm{b}}, \mathrm{Ahmad}^{\mathrm{a}}$, Syed M. (2002). A novel chalcone from Garcinia nervosa. J. Chem. Research (S). 231-233.

[6] Deachathai, S., Mahabusakaraman, W., Phongpaichit, S., Taylor, W.C. (2005). Phenolic Compounds from Garcinia dulcis. Phytochemistry. 23. 130-137.

[7] Peres, V., Nagem, T.J. Oliveira, F.F. (2000), Trioxygenated Naturally Occuring Xanthones.Phytocemistry.55.684-710.
[8] Ali, S., Goundar, R., Sotheeswaran, S., Beaulieu, C., Spine, C. (2000). Benzophenones of Garcinia pseudoguttifera. Phytochemistry. 53. 281-284.

[9] Sari, R. dan Hanan, A. (2000). Garcinia (Clussiaceae) di Kebun Raya Bogor: Fisiognomi, Keanekaragaman dan Potensi. Prosiding Seminar Hari Cinta Puspa dan Satwa Nasional. Kebun Raya Bogor

[10] Cairns, Donald. (2008). Intisari Kimia Farmasi, Edisi 2. Jakarta: EGC.

[11] Ito, C., Miyamoto, Y., Nakayama, M., Kawai, Y. (1997). A Novel Depsidone and Some New Xanthones from Garcinia Spesies. Chemical and Pharmaceutical Bulletin. 45 (9), 1403-1413.

[12] Nedialkov, P.T. Kitanov, G.M. (2000). Two benzophenone0 arabinosides and a Chromone from Hypericum annulatum. Phytochemistry. 59. 867-871

[13] Chin, Yi-Ping, Huang, Wei-Jan, Hsu, Feng-Lin, Lin, Yuh-Ling, Ling, Mei-Hsuang. (2011). Synthesis and Evaluation of Antibacterial Activities of 5,7-Dihidroxycoumarin Derivatives. Arch. Pharm. Chem. Life Sci. 11. 386-393 